\title{
A view of computer music from New Zealand: Auckland, Waikato and the Asia/Pacific connection
}

\author{
WILLIAM DART, $\dagger$ JOHN ELMSLY †† and IAN WHALLEY \\ $\dagger$ The University of Waikato, Private Bag 3105, Hamilton, New Zealand \\ $\dagger \dagger$ The University of Auckland, Private Bag 92019, Auckland, New Zealand \\ §The University of Waikato, Private Bag 3105, Hamilton, New Zealand \\ E-mail: †wdart@waikato.ac.nz,††ja.elmsly@auckland.ac.nz,§musik@waikato.ac.nz
}

Dealing predominantly with 'art music' aspects of electroacoustic music practice, this paper looks at cultural, aesthetic, environmental and technical influences on current and emerging practices from the upper half of the North Island of New Zealand. It also discusses the influences of Asian and Pacific cultures on the idiom locally. Rather than dwell on the similarities with current international styles, the focus is largely on some of the differences.

\section{INTRODUCTION: CULTURE, ENVIRONMENT AND RECENT CHANGE}

The upper half of the North Island of New Zealand includes over half the country's population, with Auckland and Waikato being two of the four most populated regions according to the 2001 Census. The area includes the main economic and export bases of the country, and Auckland is consistently ranked in the top ten cities to live internationally by Mercer's Worldwide Quality of Life Survey. In comparison to the rest of New Zealand, the region is characterised by a rapidly declining European population, an increasing Asian population that is projected to double by 2016 , and a diversity of Polynesian cultures.

Until the 1950s, New Zealand history was largely retold in our schools through a British colonial perspective. More recently, cultural changes have been brought about by an increasing Maori political and economic voice as grievances are raised and settled under legislation respecting the Treaty of Waitangi, a legal agreement between the British Crown and the indigenous people. Increasing links to North East Asia through trade and immigration have also added to a sense of cultural diversity.

For many years, New Zealand's geographic isolation from European cultural centres resulted in excessive authority being bestowed on people educated abroad, or successful expatriates. This was an inevitable part of an adolescent country suffering from 'colonial cringe' derived from its British heritage. Unsure of its own values, New Zealand inevitably looked outward to Europe and especially England for confirmation.

The last thirty years has seen a gradual reversal in this view. The society has simply grown up and no longer feels the same need to be defined from off shore. This is partly due to the country's demographic change towards similarity with nations such as Canada, the USA and Australia, established over the years by immigration. The ethnic and cultural diversity in New Zealand is in stark contrast to established cultures like Japan, Germany or France. A significant proportion of the population was not born in the country, nor in Britain, and is at ease with more than one culture.

Particularly in the upper half of the North Island of New Zealand, this diversity results in a splintering of a commonly shared background, making culture a melting pot of Asian, Maori, Pacific Island, European and English inheritances. The result is fluid, evolving and negotiated: North meets South, East meets West, and the old meets the new.

Reinforcing this is the short-time scale of local history. New Zealand was one of the last places on earth to be settled. Organised European colonisation only began around 1840, and Maori settlement dates from 1300 1400. History is then a weaker defining characteristic of national identity than in many developed nations. One's historical sense of continuity is usually constructed from off shore, and depends on individual ethnic background and international perspectives.

New Zealanders are avid international travellers, adding to their ease in cultural appropriation and sense of looking outward. Frequent trips to 'home countries' add to this. Curiosity about and an interest in other countries is an expected component of one's continuing education.

New Zealanders have also been early adopters of new technology. The country has one of the world's best telecommunications infrastructures and still leads as one of the most 'connected': an assumed notion that results in many disappointments when New Zealanders visit other 'developed' countries.

With a landscape that ranges from a tropical to alpine environment, New Zealand is the world's largest Pacific island. Its proximity to the sea, sense of space and light, and its 'clean green' image are constantly occurring icons in its tourist brochures. It is an awareness of the natural rather than human-made environment that provides similar experiences, and binds together an evolving local culture. 


\section{AUCKLAND AND WAIKATO UNIVERSITIES}

Electroacoustic and computer music practice in New Zealand, in the sense of it being used to create unique musical idioms rather than replicate existing styles, tends to be based around educational institutions with attached research and artistic programmes. The upper half of the North Island includes The University of Auckland and The University of Waikato. Both are directly involved in computer music through their music departments. There are also strong cross-disciplinary programmes at Elam (the Fine Arts School and Auckland University) and Auckland University of Technology (as part of multimedia studies).

\subsection{The University of Waikato}

The newest university music department in New Zealand is at the University of Waikato, which first offered a major in music in 1991. Although studios operating completely in the digital domain were established then, it was not until 1996 that they were set up in a purposebuilt two-room space. Over the last ten years, the department has set up the professional B.Mus./M.Mus. degree programme that extends to doctoral level. A multi-venue performing arts complex has recently been completed and opened in March 2001.

The three-year undergraduate digital music programme (Music and Computers, Composition for the Screen, and Electroacoustic Music) is now the largest in New Zealand universities, supporting the rapidly growing graduate programme. Technically, it covers sequencing and production, sample manipulation and synthesis generation, and work with MAX/MSP and Supercollider. The undergraduate courses also contribute to a conjoint multimedia programme run by the Department of Computer Science. Common research interests between the departments ensure ongoing technical research and artistic output in computer music.

Composer, author and producer Ian Whalley established and directs the studio teaching and research programme. In 2000, Senior Tutor Lisa Merridan-Skipp assisted him, appointed later as Lecturer and Studio Director at Victoria University of Wellington beginning in 2001.

The focus of the studios is on composition to produce music in a variety of settings, rather that using digital equipment to record live performance. The state-of-theart current studio configurations are on the website (www.waikato.ac.nz/music). The set-up is controlled by a high-speed $(1 \mathrm{GHz})$ digital network and driven by a central server, where a substantial amount of the funds invested have been allocated. An advantage is that a studio can be individually configured for each user as they $\log$ on, and the 'studio' is in reality a network of computers that can be accessed both on and off campus. The new concert hall is extensively digitally wired so it can be included in our network, and used for multimedia and Internet broadcast.

The main studio set-up allows for full TDM Protoolsbased fifty-six-track digital mastering, and the Department recently produced and released the NZ Sonic Arts 2000 CD (December 2000), a collection of works from New Zealand electroacoustic composers including John Young, John Elmsly, Michael Norris, Miriama Young, Chris Cree Brown, John Rimmer, Matthew Suttor, Lisa Meridan-Skipp and Dugal McKinnon. Composer Jack Body describes the collection in his review as:

... an ear-tingling, brain-scrambling taste of the current state of New Zealand electroacoustic composition... it continues to stimulate my listening and thinking. I've listened to this disc several times and it continues to stimulate my listening and thinking. There is so much variety here, and so much technical brilliance.... (Body 2001)

Intended to be the first in a series documenting electroacoustic music by New Zealand composers, the CD illustrates some of the range of approaches being undertaken. It also updates one of the last major releases of New Zealand electroacoustic works by Ode Records (1993). This was a seven-CD series that featured Jack Body, Denis Smalley, John Rimmer, Ross Harris, John Cousins and then-emerging composers David Downes and Kim Dyett.

The university was the original gateway for the Internet into New Zealand, and we are fortunate to have a first-rate digital infrastructure. The Department recently set up and hosts the new website for Australasia Computer Music Association (www.acma.asn.au), with its associated listserv group, acma-1.

The Computer Science Department (www.cs.waikato. ac.nz) has an established international reputation as a leading centre through being involved in a wide range of innovative research involving government-funded research projects and group projects. Most relevant to music are the New Zealand digital music library (www.nzdl.org/musiclib), a web-based melody indexing service, and an optical music recognition service, currently available in a demonstration mode only (Bainbridge and Carter 1997). Also important to music is the Machine Learning Laboratory (http://www.cs.waikato. ac.nz/ ml/). The Laboratory aims to produce a state-ofthe-art machine learning workbench, to investigate the fielded application of, and to develop new approaches to, machine learning. Its application to music is beginning to be explored (Witten, Manzara and Conklin 1999).

\subsection{The University of Auckland Studios}

The University of Auckland Composition Studios were established in 1976 by John Rimmer, with the introduction of the new B.Mus. curriculum. Looking ahead to an expanded electroacoustic programme, Rimmer arranged 
an exploratory tour of overseas studio facilities at the end of 1976, meeting John Chowning and Leland Smith at Stanford, and fellow New Zealander Barry Vercoe (MIT). CSound was to become a favourite tool for Rimmer as a consequence. Further visits were to Vancouver, where Barry Truax was developing the POD system; to Barry Anderson at West Square, Peter Manning in Durham, Glasgow, and Zinofiev's Putney studio, Stockholm's EMS, Utrecht's Institute of Sonology. However, it was not always the major studios that made the strongest impressions, and Rimmer talks with fervent enthusiasm of Ton Bruynel's private studio and his personal concepts of and approaches to composition. Back from his investigative tour, Rimmer began obtaining more mixing and synthesis apparatus for the University, a first important step being the micro-pin panel matrix mixer built by Will Gailer, modelled on one established in the Victoria University of Wellington studio by Douglas Lilburn.

The studio equipment has followed most of the developments of the last quarter-century. The original studio was centred on the EMS VCS3, the classic British voltage-controlled synthesizer, and one that is still used for demonstration purposes. A larger modular synthesizer, the Roland System 700, was later purchased with one of the now historic MC-8 MicroComposer units which allowed pre-MIDI sequences to be stored on cassette. The first computer in the studio was the Apple II with a Mountain Hardware sound card and Alpha Syntauri keyboard. The closed nature of this system led to it being neglected once the DX7 and MIDI appeared, and a succession of Commodore, Atari and Macintosh computers were used for sequencing and then digital editing.

Composer John Elmsly, who joined the staff of the School of Music in 1984, currently directs the Studios. There are two purpose-built rooms with links to the adjacent Music Theatre, a recording venue with a soughtafter acoustic for chamber music recordings, and Macintosh-based recording and editing facilities. Nearing completion are additional sound-editing and recording facilities with possible digital broadcast facilities in the University's new School of Creative and Performing Arts facility. Students also have access to workstations in the Faculty of Arts Multimedia Laboratory.

The School of Music studios are composition oriented, intended to serve the needs of undergraduate and graduate composers wishing to explore the possibilities of the medium, as well as providing a large number of students with a working knowledge of the idiom. Most of the composers who have studied in the Department have worked in the studio, and composers have always been encouraged to include both acoustic and electroacoustic study in their courses.

In 1997 the Australasian Computer Music Association's annual conference, Interface 97, was hosted by the School of Music with composers from Australia, New Zealand and further afield attending conference papers and numerous concerts. It also involved staff and student performers from the Karlheinz Company, the Auckland Philharmonia and the New Zealand Symphony Orchestra.

The two composition-focused undergraduate courses in Electronic Music cover editing methods, sound synthesis, MIDI/sequencing, FM synthesis, sample editing, and introduce a variety of current software packages. A new introductory course on Music and Technology is proving very popular with students, including non-music majors. Postgraduate students have produced work which ranges from abstract synthesis-based composition to programming and research into interactive systems.

Around forty students each year are involved at various levels of studio work that has included music for theatre, dance, film and video, and interactive compositions. The group is a mixture of music majors and students from Film Studies, Science, Fine Arts, Architecture and Engineering.

Graduates have opted for further study in the United States at Brooklyn, Columbia and Princeton. Others have joined the staff of Television NZ and Radio New Zealand, worked in the music industry, taught at institutions like the School of Audio Engineering, or in secondary schools where some have been involved with special software development projects.

The studio was one of the first users of DAT in New Zealand, and has a substantial recording history, with the facilities frequently used for CD editing and mastering. The current configuration has ProTools workstations and a variety of digital and analogue synthesis and processing software and hardware. The transition to digital equipment is seen in the current studio configurations found at http://www.mus.auckland.ac.nz/pages/ studios.html, which mixes both analogue and current digital media to allow maximum flexibility of production methods to student users.

\section{CURRENT LOCAL DEVELOPMENTS AND INFLUENCES ON COMPUTER MUSIC}

\subsection{Historical and international connections}

New Zealand electroacoustic music began with the work of Douglas Lilburn (b. 1915) who established the studios at Victoria University of Wellington in the 1960s. Lilburn gave the idiom a distinct New Zealand voice with an emphasis on using local environmental sound as source material, and thinking in sound images rather than music, all of which was in sharp contrast to the electronically generated sounds favoured in, say, Cologne. His approach influenced a younger generation of composers who worked with him in the studios such as John Rimmer, John Cousins and Denis Smalley.

Lilburn's pioneering sense remains very much part of the New Zealand attitude to composition: a 'jack of all trades' and 'do it yourself' approach coupled with a 
healthy sense of enquiry. It combines a mixture of irreverence and deference to established practices overseas coupled with a low-level orthodoxy, and a sense of appropriation and synthesis.

Partly this is a reflection of the national state of cultural development: a sense of fluidity where one can 'mix and match' material freely (Whalley 2000d). New Zealand is not characterised by strong schools of musical thought or a common sense of musical history in folk tradition, and many composers avoid adopting a dogmatic approach to one aesthetic.

As in most countries, electroacoustic art music locally has never been a commercially viable proposition and without educational institutional and government funding support, would be unlikely to exist with the degree of profile it has managed to sustain. It also relies on the international network of conferences, festivals, sabbatical leaves, and continuous academic granting of credentials to be sustained and legitimised.

As an international art form that exists mainly through connection with international events and cyberspace, it is ideally suited to a New Zealand artistic perspective. Personal connections based on artistic interests allow each composer to follow his or her own path.

Many New Zealand composers working in the idiom travel widely and make frequent contributions to international festivals, conferences and published research in the Northern Hemisphere. Travel distances mean that it is economically expedient to spend long periods away from the country, a pattern reflected in post-graduate continuing study in centres such as New York and London. A recent characteristic of this travel is that apart from the usual English/French-speaking connections in Canada, France, America and England, there are also frequent links to other research in countries such as Germany, Japan and Italy.

Aspects of Lilburn's influence remain, but there is now a greater sense of stylistic diversity largely influenced by the variety of available international styles and techniques available. A result is the local art form remaining benchmarked to an innovative international standard, yet at times artistically expressed through a set of cultural conditions that are unique to New Zealand.

\subsection{Acoustic and electroacoustic connections}

Many New Zealand composers work across acoustic and electronic/computer music media, and experiment with freely combining the idioms.

John Rimmer's pioneering Composition series for various soloists and ensembles, beginning with a work for solo horn in 1968 and ending with one for double bass, was inspired by a Giacometti sculpture exhibition in New York. It was new territory in this country. Rimmer states: 'In 1968, in my naïve way, I wasn't aware of any problems - I simply juxtaposed the horn and electronic sounds together.' (Dart 1988: 9)
Rimmer again illustrates the flexibility of the acoustic/ electroacoustic approach. In 1975 he composed two works, acoustic and electronic, both with the same title. The composer notes:

Where Sea Meets Sky began life as an electronic piece: Where Sea Meets Sky 1 was based on some cloud drawings that I made on a flight from Sydney to Auckland and Where Sea Meets Sky 2, is an outgrowth of the original electronic piece but for instruments, so it's a kind of reverse procedure ... instead of working from instruments to electronic sounds, which one can do, so that the electronic sounds become an extension of the instruments, it's the other way around. (Dart 2000a)

John Elmsly's work in this genre includes Echoes and Chorus (1981) for clarinet, the MIDI-generated Triptych (1985) for trumpet, Gestauqua (1989) for brass quintet, and the largely granular synthesised Drift (1994) for viola and tape. In Gestauqua, the composer 'designed his electronic sounds not only to blend musically with the brass instruments generally, but even to match the specific tone qualities of our group' (Cooper 2000). Drift covers a wide emotional range with its sampled and granulated viola sonorities.

Another impressive work is Matthew Suttor's 1994 Rugwerk for flute and electronic sounds, with its subtle transformations of flute sound blending into the acoustic texture.

Due to the influence of John Rimmer and his connections with Barry Truax, but also because of Murray Schafer's visit to New Zealand in 1973, The University of Auckland has always favoured a soundscapeinfluenced approach to composition, in both electroacoustic and instrumental composition (Elmsly 2000: 33). This extends to acoustic works exploring and expanding traditional approaches to sound generation. Eve de Castro-Robinson's 1998 Chaos of Delight III, an evocation of native birdsong for women's voices, is just one example.

\subsection{Maori, Pacific and Asian instrumental connections}

Regional acoustic instruments and performance gestures have also influenced electroacoustic music. The CD Te Ku Te Whe (Melbourne and Nunns 1994) features a number of contemporary pieces played on traditional Maori instruments, yet recorded with heavy reverb at times, giving the impression that the sounds might have been electroacoustically generated. It remains one of the most original works to come out of this country, pointing to a unique source of original material yet to be fully explored. The Waikato-based composer Hirini Melbourne has also begun to explore the combination of traditional instruments and contemporary media.

Other New Zealand composers have used Maori instruments and idioms in both acoustic and electroacoustic works. Gillian Whitehead's 1997 acoustic 
work Ipu, for example, involves a combination of classical, jazz and pre-European Maori instrumental styles. Kit Powell's work for trombone and tape, WHALE (1993) asks the soloist to imitate a Karanga (Maori prayer) which underlines the climax of the piece.

The connection to Maori instruments in electroacoustic music is largely one of common sonic reference. Traditional instruments are wonderfully evocative of the ambience and space of the New Zealand landscape, their economy and subtlety being reflected in much New Zealand electroacoustic music, beginning with Lilburn's The Return (1965).

Other Pacific and Asian instruments have found their way into a number of works, through instrument and tape combinations, computer music works, or through the use of physical modelling synthesis to build composite new instruments.

Philip Dadson is one of our leading figures in the fields of intermedia. In 1974 he founded From Scratch, adapting the philosophies of Cornelius Cardew into a South Pacific context, using elements of theatre, sculpture and ritual. Large custom-built instruments made from industrial plastics create a rhythmic interplay evocative of Cook Island log drumming. His 1998 Global Hockets collaboration with German computer artists Supreme Particles, premiered at the 1998 Wellington International Festival and was later taken to Europe. Dadson (1999) describes this as 'analogue joins digital and electronic joins acoustic in a hockety mix of modes and media'.

Ian Whalley's recent work, which is entirely computer generated but sounds largely acoustic, actively explores the Asia/Pacific connection. Inucm (1997), for example, uses wind synthesis to generate short fragments and small gestures influenced by flute music from the East Sepik region of Papua New Guinea. Physical modelling synthesis is used extensively in Ga no Mita Mono (1998) to create new wind instruments at times based on shakuhachi gestures that trigger a number of synthetic scales (Whalley 2001b).

Composer Jack Body has also been a major force in using Asian sonic source material. His 'documentary' approach using environmental sounds from Indonesia is explored in Suara (1993). The 1976 work, Musik dari Jalan, awarded a prize at Bourges in that year, draws on Indonesian street sounds without too much modification. As the composer comments, 'I loved the music so much in its natural state I didn't feel inclined to transform it too drastically - it had to retain its original integrity.' (Dart 2001b)

Body is a gamelan enthusiast and is particularly engaged with the transcription of ethnic music within his own scores. Interior (1987) has the composer's own field recordings of three Chinese folk pieces played against the contributions of seven live instrumentalists, an attempt 'to frame found music into another context. It would have been very nice to have had the Chinese musicians there in person and put them into the ensemble but of course that wasn't possible.' (Dart 2001a) Eleven years later, Body would achieve this ideal when he used two Chinese folksingers on stage in his opera, Alley.

This is not to suggest that New Zealand composers have been restricted to using instruments or scales from the Asia-Pacific region. For example, Susan Frykberg on her electroacoustic CD, Astonishing Sense of Being Taken Over By Something Far Greater Than Me (1999), explores a variety of Middle Eastern scales in combining an array of current electroacoustic music generation techniques with live performance.

Nor is the influence of local sound sources limited to indigenous people. Regional accents of New Zealand speech also add to the flavour of electroacoustic documentary composition works such as Miriama Young's Speak Volumes (1998). This is also reflected in a number of tracks from Susan Frykberg's recent Astonishing Sense, part of the Audio Birth Project. 'Margaret', 'Astonishing Sense' and 'I Didn't Think Much About It' are built from interviews with the composer's family members recalling the process of pregnancy and childbirth to create narrative soundscapes.

\subsection{Sound culture, installations and mixed media}

The New Zealand electroacoustic tradition is also enlivened with mixed media events. In July 1989, Artspace, Auckland's alternative art venue, hosted the first Soundwatch, a festival of intermedia artists who bridged the gap between the sonic and the visual. The festival included a variety of artists, from composer and guitarist Ivan Zagni to the improvisation-based Clarinet Collective. The three musicians of Drone presented a challenging set combining:

... the visual - an enormous revolving 'washing-line' with speakers attached - and the aural - three live performers in miner's helmets complete with light and microphones playing electric guitar, keyboards, violin and cello among other things. (De Castro-Robinson 1989: 60)

This concept has been revisited over the last decade, the most recent manifestation being 1999's Soundculture that included John Lyall's Requiem for an Electronic Moa, a large flightless pre-European bird. The challenging diversity of Lyall's very theatrical presentation is caught in Smic's freewheeling description: 'Clarinet and live ballerina in black on toe shoes dances to Swan lake video surround sound crackling timber clanking ladders erection electronic squeal of virtual moas.' (Sumic 1999: 44)

The electroacoustic component of Lyall's self-styled 'opera', a lament for the extinct New Zealand bird, incorporates texts that are read out by computers: Lyall notes:

It occurred to me that a lot of time we're constructing our 
country and ourselves for tourist gaze and therefore it would be good if the text was read back to us in the voice that could be observing from that viewpoint. The American accent, and the banal reading with all the misemphases and mispronunciations are significant. These 'arias' are mournful because of their loss, their slippage, their failure to engage. (Dart 2001b)

Intermedia events take place on a regular basis in this country, one of the most recent being Auckland's Soliton in August 1999, featuring electronica, film, dance and performance (see Vaigro 2000).

Academically based electroacoustic composers freely contribute to these cross-disciplinary events. For example, in 1995 six artists (Chris Cree Brown, Philip Dadson, Michael Hodgson, John Ioane, Juliet Palmer and Gregory Wood) were invited to participate in The Fourth Window, a joint project between Artspace and Concert FM. Their contributions consisted of a gallery presentation at Artspace, and the accompanying sound recordings were broadcast nationally over Concert FM, the country's classical music network, and are now also available on CD. A further example is Asylum, a video/ dance/electroacoustic soundtrack work by composer Lisa Meridan-Skipp and choreographer Wilhemeena Gordon. It screened at the Musicwomen Aotearoa Festival in April 1999 (Soundings Theatre, Wellington).

\subsection{Environmental influences and birdsong}

Jack Body has suggested that:

Douglas Lilburn was attracted to electroacoustic music because, as a language it didn't carry the baggage of history, as did orchestral music, where one looks at a whole tradition which is European-rooted and hundreds of years old. In this new medium, one could relate to the sound environment in which one lived. One could recreate that particular acoustic and the particular sound within that environment. (Dart 2001a)

The freshness of the medium that remained to be explored paralleled the newness of this country's culture and made it an appropriate medium of artistic expression.

Environmental sound has been a clear and acknowledged influence on works by Rimmer with La Voce di Galileo using field recordings of thermal activity on White Island. The material for John Elmsly's work, such as Whispering Island (1995), was derived from granulations of recordings of a tidal pool on Rangitoto Island.

Thomson (1991: 257) notes that Rimmer gradually moved 'from a European concept of sound to one in which environmental influences have an important place'. However, the Rimmer soundscape is environmental, less in the sense of dutiful recording or complex processing of environmental sounds, than at the level of metaphor. The sounds of sea, waves, water birds and wind lie behind the dynamic shaping of his pieces and figure at an inspirational level, whether the actual material used is synthetic or taken from a field recording. Deeper concepts (life-cycles, laws of motion) also lie behind this search for natural rhythms, and all aspects of rhythm are of particular concern. Thomson quotes the composer himself: 'I believe that rhythm is the most important musical element remaining for composers to develop and refine continually....' (Thomson 1990: 117)

Jack Body often uses direct sonic quote in his work Duets and Choruses (1978), for example, was based on field recordings he made of birdcalls in Indonesia. These sounds from the real world have a special appeal for the composer:

Natural sounds have a complexity and richness which electronically generated sound struggles to imitate. Purely electronic sounds tend to date quickly as one begins to identify sound and the technology that is being used. As soon as this happens, the music loses its charm and beauty, whereas the wonderful inner life of natural sound is limitless. (Dart 2001a)

New Zealand native birdsong has been a recurring theme in electroacoustic idioms, partly because of the quality and range of source material. As early as 1967 Lilburn created his Study from One Note from one note of a kokako, a threatened native bird with a rich and distinctive resonant boom as well as a characteristic melodic signature call. John Rimmer's acoustic piano pieces, For the Kokako (1978), are also based on this bird's song. John Elmsly took this association a step further with Stilldream K (1990) for baroque flute and tape, building material around melodic fragments from the Rimmer and synthesising kokako-like sounds derived from baroque flute samplings.

\subsection{Popular music connections}

Computer music is certainly not confined to the academy. Major local exporters of dance music include Kog Transmissions (Brown 2000), a collective that covers a large spectrum of genres and distributes internationally, particularly to Europe, reflecting international tastes. Similarly, 'world music' has been extensively explored in popular music locally. David Parsons' Parikrama (2000), for example, evokes a series of soundscapes on works such as 'Dorje Ling' and 'Himalaya', extensively influenced by the music of Tibet (Parsons 2001).

A younger generation of songwriters/composers are now beginning to explore New Zealand themes that were once the province of academic electroacoustic music composers. Jordan Reyne, whose music is supported by dense sampling from pre-recorded and industrial sources - many of which have been gathered by Reyne herself - feels a strong affinity with the environment in her music. Her atmospheric setting of New Zealand poet James K. Baxter's 'High Country Weather' for the 
recent Baxter $\mathrm{CD}$ attempts to 'recreate the feeling of the exquisite yet painful loneliness of being, and I wanted to make a space around me, like if you stand on a hilltop, and think, "I'm completely alone in the universe. Isn't it terrible. Isn't it great.", (Dart 2000b).

Some New Zealand composers have drawn on popular music sources as material for their work. John Lyall finds that:

Dance music allows simple, pre-set sounds, giving you thousands of commercial samples. I steal bits of that. All that dance stuff is based on a very relentless beat - it's almost impossible to change the time signature. But, if you open up a new file and don't put any of that in, just put your recorded wave files in which instead of being 4 beats or 16 beats turn out to be something different, you've got a very good composition tool. (Dart 2001b)

In the 1970s and 1980s, many New Zealand rock musicians developed the use of 'low tech' approaches to music production. This is illustrated in the work of Chris Knox who has created much of his music using fourtrack portable cassette tape recording techniques and low fidelity guitar sound. The immediacy of this approach, and the 'grittiness' of the resulting sonic texture have become an integral part of Knox's aesthetic, and his influence can be felt in the music of fellow artists on the Flying Nun label.

A 'retro' approach is something still being explored by electroacoustic composers. Lyall notes:

I do a lot of 'retro' solutions where I take the computer and then feed the output of that through old effects, then take them to acoustic tape and do something else with them. This is not something you would do with state-of-the-art equipment and it takes you into intriguing territory. You get slippage and physicality because all the joints and transfers and translations are showing - something you can't get when you sit in the studio with everything first generation. (Dart 2001b)

John Rimmer also looks back to older analogue techniques:

I still regard myself as an analogue tape composer because I like to physically handle tapes. I like to move sliders on synthesisers. I like to turn knobs to get new pitches and so on. The traditional synthesiser is a wonderful instrument for me. (Dart 2000a)

\subsection{Aesthetics and compositional approaches}

A regimented and hierarchical division of culture, say between popularism and 'high art', 'street smarts' and academic intelligence, or the guardians and rebels of culture, is not always clear-cut in New Zealand. This often strikes composers when they return to this country, because there is the opportunity to think the unthinkable, and the chance to try new approaches that could easily be marginalised in traditional centres.

A general approach at both Waikato and Auckland
Universities has been their emphasis on composition and creativity across idioms, and the application of computers to music-making in a broad sense, without adhering to a particular style. Pragmatic and artistic outcomes in a variety of settings are explored. Drawing on artists working outside the academy and encouraging students to write for non-academic audiences have also influenced approaches. Electroacoustic music techniques are then freely incorporated into a variety of other musicmaking situations.

Many electroacoustic New Zealand composers have developed individual procedures and aesthetics that are used to guide their own work. They remain individual approaches rather than schools of thought locally, and are continuously being refined.

Switzerland-based New Zealand composer Kit Powell, for example, uses juxtaposition through sonic opposites such as dense/light, complex/simple, and chaotic/ordered: this juxtaposition is a primary method of personal expression for the composer. The function of the performer(s) is a central concern when writing a work. His compositional approach is often embedded in the use of Abelian form, where the sections of a piece also reflect the form of the whole piece, and the use of chance procedures to supply detail within sections (Whalley 2000b).

On John Rimmer's approach, Elmsly notes:

... (Rimmer) was thrilled when the real-time granular synthesis part of the POD system was developed to allow granulations of sampled sound. At last he could combine three elements dear to his concept of composition: the ability to make non-trivial use of environmental sound, to control processing gesturally in real-time, and to make use of rich, highly spatialised, digitally generated textures. (Elmsly 2000: 35)

John Elmsly's electroacoustic work attempts to create an enlarged space based upon the instrumental sounds. Sound processing is a tool in the production of works that are highly reflective, often meditative responses to and elaborations of sonic source material. He also explores the dichotomy between the totally ordered/precisely timed, and the freedoms of a quasi-improvisatory response system. Instrumental parts may contain alternative paths, or be only vaguely synchronised to electronic material, which in turn are devised to allow and profit from this.

Matthew Suttor looks to texture and pattern as musical elements to provide the most compelling emotional connection to music, and are also the most satisfying way to express ideas on the relationship between music and image. Flock (1996), for example, grew out of a computer program he adapted that imitates the flocking of birds (Whalley 2001a). He is also strongly influenced by theatrical considerations, and recent works such as Sarrasine (1999) and The Ankle Diver (2000) are multimedia events. 
Ian Whalley's work had been influenced by physical modelling synthesis as a method of generating sound and retaining a performance element in computer music (Whalley 2000a). He has also used system dynamics software to simulate emotional response to music based on listening. Extended to a generative system for composition, the software is then applied to models that simulate the dialectic between thematic material and the structure of works (Whalley 2000c).

\subsection{Technical applications influences}

Music technology that was once the preserve of the few due to its expense is now accessible to the home user. The maintenance of an art form is no longer dependent on a few composers who are privileged in having access to this equipment.

The quickest adopters of commercial music technology are young people working in new popular music idioms, and home studio users who are now writing soundtracks for a range of screen projects such as multimedia and industrial video. The adoption of this new technology by popular music practitioners is the continuation of a trend of technological literacy that is integral to the modern rock and popular music aesthetic. Technological fluency in this idiom is, in some cases, more important than traditional musical fluency (see Jones 1992, Negus 1992).

To the mid-1980s, the study of electronic music attracted few people in tertiary music departments. Perhaps this was due to the expense in equipping studios and the variable career-usefulness of the skills learnt. With decreasing cost and the use of home PCs, digital dabbling in music is now the province of many. Independent of the university programmes, this introduction to the world of music composition is increasingly common. It often begins with using MIDI and sampling, or notation software to help conventional composition practices. The idea that digital music is solely a process by which to make known styles easier to replicate abounds.

Also evident through the new dabbling approach is a diminishing sense of performance value. The computer is becoming the first instrument of many rather than the piano, guitar or a wind or string instrument. A resulting shift in a sense of musical authenticity is also becoming apparent. If one's primary musical input is from MIDI/ synthesizer-generated music rather than live orchestral music or rock music LPs, stylistic and sonic frames of reference differ from the conventional.

Yet, extensive digital literacy does not necessarily equate with musical or sonic literacy. It is a problem that most electroacoustic educators seek to address in combination with the provision of extensive practical composition skills. Jack Body from Victoria University of Wellington, for example, maintains that:
Composing is basically hard work. One wrestles with something, looks at lots of solutions, dismisses this or that and finally comes up with something that might not be very long or sound very complicated. But one has arrived at that through a certain process. It might sound masochistic, but it has to do with the idea of a composition being a considered process of creativity - it's not just fiddling or playing around. (Dart 2001a)

\section{EMERGING DEVELOPMENTS}

Discussing emerging developments is fraught with difficulty. Any comments can only serve as an historical snapshot.

At the University of Auckland, small-scale funding and technical support of multi-user studios has tended to mean reliance on relatively simple and portable set-ups and limited software/hardware development. The focus is largely on composition using existing software packages though often in unorthodox ways, but there is an emphasis nevertheless (possibly also because of the environmental interests) on the intrinsic qualities of the sounds used or produced, and thoughtful structuring of resultant compositions. Whether the process used is high- or low-tech, invented or borrowed, has not been the primary concern for most of the composers working with electroacoustic composition in Auckland.

Realtime work has developed slowly, though explored at various times by Rimmer and Elmsly, with some significant student input to particular projects. Recently there has been experimentation with Max/MSP, though the finished work has been limited to a digital reworking of John Rimmer's Marathon (1982) for cello and delays. Ex-Auckland student Mark Storey has also been working on interactive projects involving MAX and various sensors.

The University of Waikato was fortunate to be able to equip its studios directly in the digital domain and was supported by funding levels to meet a growing interest in computer-based approaches to music. Taking advantage of the University's high-speed local network, research and practice is increasingly moving into interactive composition, and digitally based performance/inter-media.

A recent joint research proposal between the Departments of Music and Computer Science seeks to develop an emotion-based nonlinear automated composition system. The work draws together a number of different research threads being pursued on campus, and centres on developing affective music computing research (Hashimoto 1997) in combination with locally developed artificial intelligence software tools.

Waikato's recent proposals also include trialing an Internet-based collaborative composition project between New Zealand Music Departments. The new performing arts complex also supports our interests in the net broadcasting of multimedia/live performance works, and adds a professional standard of digital recording of acoustic events. 
In New Zealand, artistic developments in electroacoustic music have largely paralleled the creative use of recent and evolving hardware developed overseas. The country has never been a significant developer of electrically generated new music hardware, but an innovative adapter of it. Net-based activities and developments, with comparatively low capital entry requirements and a cyber rather than geocentric nature, are well suited to a New Zealand approach, and it is a medium likely to be increasingly explored.

The speculative question that remains is whether, in an Internet-connected world with an increasing sense of internationalism and ease of access to music production technology, regional variations will continue to develop as they did in an analogue world.

\section{CONCLUSION}

New music often results from the dialectic between art and new technology. The adventurous have historically been early adopters, adapters and inventors. Given that New Zealand is characterised by the rapid adoption of new technology and the country is often used as a testing ground for new devices, it is fertile ground for new artistic insights.

New music has often come from a blend of internationalism and regionalism, as the blues demonstrates. It is often in the netherworld between the permissible and the possible, through cultural and political diversity, and where new experience meets the narrative weight of history and culture, that new art forms are produced, and the most innovative work can often occur.

New Zealanders have and continue to play a leading role in the cutting edge of this research effort. Examples include Robin Maconie (Stockhausen's biographer), Barry Vercoe (of CSound, now at MIT), composer Denis Smalley (Professor of Music at City University, London), and Barry Anderson ('British' electroacoustic music pioneer). With the decreasing cost of travel and Internet-based communication, fewer have found the need to relocate to make an international contribution.

\section{REFERENCES}

Bainbridge, D., and Carter, N. 1997. Automatic recognition of music notation, In H. Bunke and P. Wang (eds.) Handbook of Optical Character Recognition and Document Image Analysis, pp. 557-603. Singapore: World Scientific.

Body, J. 2001. Music in Zealand, No. 38, Summer 20002001: 64 .

Brown, R. 2000. Dancing Kings. Unlimited, December 2000: 58-64.

Cooper, G. 2000. Liner notes. Points in a Changing Circle. Atoll ACD299.

Dadson, P. 1999. Liner note. From Scratch: Global Hockets Live in Europe. Scratch Records.

Dart, W. 1988. John Rimmer talks to Music in New Zealand. Music in New Zealand 1: 7-13, 40.
Dart, W. 2000a. Appointment with John Rimmer. Broadcast on New Zealand Concert FM, 16 June.

Dart, W. 2000b. New Horizons. Broadcast on New Zealand Concert FM, 8 July.

Dart, W. 2001a. Interview with Jack Body (unpublished).

Dart, W. 2001b. Interview with John Lyall (unpublished).

De Castro-Robinson, E. 1989. SOUND/WATCH: The contemporary edge at Auckland's Artspace. Music in New Zealand 6: $20-3$.

Elmsly, J. 2000. Beyond the sound, the electroacoustic world of John Rimmer. Music in New Zealand 36: 32-6.

Hashimoto, S. 1997. KANSEI as the third target of information processing and related topics in Japan. Proc. of the Int. Workshop on Kansei - Technology of Emotion, pp. 101-4. Tokyo, Japan.

Jones, S. 1992. Rock Formation: Music, Technology and Mass Communication. Newbury: Sage.

Negus, K. 1992. Producing Pop. London: Edward Arnold.

Parsons, D. 2001. http://www.harmonies.com/bios/parsons. $\mathrm{htm}$

Sumic, J. 1999. Soundculture '99: footnotes in Folie FX and Eliptical Fields. Art New Zealand 91: 40-5.

Thomson, J. M. 1990. Biographical Dictionary of New Zealand Composers. Victoria University Press.

Thomson, J. M. 1991. The Oxford History of New Zealand Music. Oxford University Press.

Vaigro, W. 2000. Soliton '99. Art New Zealand 94: 36-9.

Whalley, I. 2000a. Real time to hyper-real gestures: expanding instrumental expression through physical modelling synthesis. Proc. of the 10th Int. IASPM Conf., pp. 395-401. University of Technology, Sydney, Australia, 9-13 July.

Whalley, I. 2000b. Kit Powell: changing approaches and New Zealand sounds. Music in New Zealand 36: 30-1.

Whalley, I. 2000c. Applications of system dynamics modelling to computer music. Organised Sound 5(3): 149-57.

Whalley, I. 2000d. Interview with John Elmsly and Lisa Meridan-Skipp (unpublished).

Whalley, I. 2001a. Matthew Suttor: visualising music and things theatrical. Music in New Zealand 38: 42-4.

Whalley, I. 2001b. Redundancy, innovation and integration: digital music techniques and neo-world music. Proc. of the KlangArt Congress 1999, pp. 190-203. Osnabrueck University Press.

Witten, I., Manzara, L., and Conklin, D. 1999. Computational Models of Music Prediction. Los Alamitos, CA: IEEE Computer Society Press.

\section{DISCOGRAPHY}

Baxter. 2000. New Zealand National Radio/Universal 98422.

Body, Jack. 1993. Suara. Ode Record Co. CD Manu 1380.

Cousins, John. 1993. Sleep Exposure. Ode Record Co. CD Manu 1436.

Downes, David. 1993. Saltwater. Ode Record Co. CD Manu 1435.

Dyett, Kim. 1993. Wallpaper Music. Ode Record Co. CD Manu 1438.

Frykberg, Susan. 1999. Astonishing Sense of Being Taken Over By Something Far Greater Than Me. earsay, es 98003.

Harris, Ross. 1993. Inner World. Ode Record Co. CD Manu 1434. 
Melbourne, Hirini, and Nuns, Richard. 1994. Тe Ku Te Whe. Rattle Records, RAT-D004.

New Zealand Electronic Music. 1975. Kiwi Pacific Records 1975 TCLD54.

New Zealand Electronic Music. 1975. Reid Pacific Records 1975 SLD-44/46.
New Zealand Sonic Art 2000. The University of Waikato. MDUW 1200.

Rimmer, John. 1993. Fleeting Images. Ode Record Co. CD Manu 1437.

Smalley, Denis. 1993. Tides. Ode Record Co. CD Manu 1433. The Fourth Window. 1999. Artspace, Auckland. 